\title{
Rainbow Of Followers' Attributes In A Leadership Process
}

Evgenia V. Prilipko University of the Incarnate Word, USA Absael Antelo, University of the Incarnate Word, USA

Richard L. Henderson, University of the Incarnate Word, USA

\begin{abstract}
While the breeze of leadership is swaying the continent of North America with irresistible appeal, followership is left to rest in the shade. The subject has been given a very limited attention, thus, the paper attempts to address this deficiency and propose attributes of effective followers. Statistical survey design and correlation procedures are applied to assess selected variables and their relationship when examining the results of a multicultural survey conducted among leaders and followers of six countries. The results of the sample countries Russia and Belarus are being reviewed. Findings indicate that respondents tend to have an involuntary inclination towards group work and camaraderie, and are comfortable in the atmosphere of togetherness. Results also illustrate that respondents of the sample have a different understanding of notion of tolerance than respondents in the United States. The study discusses the need to understand how individual traits are assessed and developed, and how individuals can be formed, nurtured and prepared to become effective followers. The criticality of certain attributes characteristic to followers is examined along with practical suggestions of how some attributes can be brought to a more advanced level. The significance of having a leader inside every follower is emphasized. Uncomplicated, yet effective strategies on how to unleash and sustain followership capacity in individuals are described.
\end{abstract}

Keywords: Followership; followers; attributes of followers; effective attributes of followers; leadership

\section{INTRODUCTION}

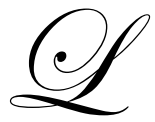

eadership cannot exist without some degree of followership (Hollander \& Kelly, 1992; Lundin \& Lancaster, 1990; Vecchio, 1987). Similar to a yin-yang harmonious interdependency, effective leadership implies effective followership. The ancient concept of the yin-yang dichotomy is a fundamental principle in traditional Chinese culture. Also known as Two Standard Powers, yin and yang are inseparable. "Yin is still and cumulative, while yang is mobile and circulating" (Lin, 2000, p.20). Therefore, we view leadership and followership as a symbiotic relationship where leadership acknowledges and respects the professional, knowledgeable, experienced, skilled and trustworthy contributions of followership. Building followership capacity can be compared to "tapping into the reservoir" (Slater, 2008, p.58) of "underutilized talent within an organization" (Barth, 2003, p.62) and "thereby providing others with the opportunity to shine, to share their talent and to contribute to the work" of the organization (Slater, 2008, p.58).

According to Kelley (1988), the views of leadership are more developed and advanced compared with the views of followership. As Vecchio (2002) states, a number of models exists that detail dimensions of leadership, whereas there are "no formal models that detail styles or dimensions of followership" (p.659). In fact, followers constitute the key audience for leaders. Leaders do not exist without followers (Yukl, 2006). "While leaders contribute a maximum of $20 \%$ to organizational success, followers contribute an estimated $80 \%$ to the success of the organizations" (Kelley, 1992).

Followership is a complex phenomenon and being an effective follower is a lifetime process of carefully selecting a bouquet of skills and competencies, based on experience, intense practice and learning. Expertise is a 
gradual age-related maturation process; layers of differentiated skills and acquired knowledge grow to become fully formed competencies. It is suggested that characteristics of experts' brilliant performance are "acquired through extensive experience" (Day, Harrison, and Halpin, 2009, p.179). The effect of practice on expert performance is critical (Chi, Claser, and Farr, 1988). In accordance with Ericson (1996), and Ericson and Lehmann (1996), "a minimum of 10 years or 10,000 hours of concentrated practice is needed to attain rudimentary levels of elite performance associated with expert status in a given domain" (as cited in Day et al., 2009, p.179).

Our purpose is to investigate the effectiveness of proposed follower attributes by examining their validity and establishing a platform of the coherent process of follower refinement. We view follower development as a colorful rainbow of attributes which compose their innermost layer and, simultaneously, present their individuality and uniqueness. It is important to acknowledge that underneath the rainbow of attributes, there are individual fundamental patterns of behavior, attitudes, aspirations and beliefs. The most obvious of those behaviors are the skills that are easily observable by the others in the workplace. They are individual characteristics, which, in the course of time become easily predictable. "One's identity is a multifaceted and dynamic composite of attributes, values, knowledge, experiences, and self-perceptions" (Baltes and Carstensen, 1991).

Aristotle once noted (Goffee and Jones, 2006) that "all great leaders must first learn to follow." Although the traditional view is that "leaders act and followers mainly react," as discussed by Avolio (2007), the opposite is also true: "Leaders also are followers, and followers also exhibit leadership" (Hackman \& Wageman, 2007, p.45). Authors Townsend and Gebhardt (2003) concur with that conclusion by saying that "all employees, including leaders, exhibit followership behaviors at some time or another." Hackman and Wagemen (2007) argue that "It can take a good measure of skill and personal maturity to balance between one's simultaneous roles as leader and as follower" (p.46).

This article begins by presenting a general overview of the followership concept and its importance in modern organizations. It then proceeds to carefully examine each of the follower attributes identified. Each attribute is portrayed through extensive literature. Additional support for each attribute is drawn based on multiple theories and examples designed to trigger the readers' visualization in order to capture the validity of attributes in the most comprehensive way. The article also examines the implications of multicultural research conducted and the results of data collected. The article presents effective techniques that followers may use to develop effective relationships in the workplace that pave the way to building strong follower-follower and follower-leader bonds. Finally, the article considers the implications of the following theories in relation to proposed collection of follower attributes: Relationship/social capital concept, Social Exchange Theory, Psychological Contracts Theory, Reciprocity Principle, Equity Theory, Attribution Theory, and Theory of Integrative Development.

\section{STATEMENT OF THE PROBLEM}

"It is not clear why individuals choose to become leaders" or are assigned leadership roles, "and it is even more puzzling why people voluntarily submit to leaders and become followers" (Van Vugt, 2006, p.355). Although, the literature provides a plethora of leadership approaches, the leading process still remains as the most observed, but least understood human action. Some studies on leadership have produced significant findings which have helped to differentiate between leader and follower personal attributes and their consequent behaviors (SEDL, 1992). However, little attention has been given to the followers' contribution to the leadership process.

\section{PURPOSE OF THE STUDY}

Follower characteristics have not been given a fair amount of attention, and, according to Hur (2008), they have been "buried in the study of the leader-follower relationship" (p.367). Although Hersey and Blanchard (1982) view followership characteristics as "one of the independent variables of the leadership process," current paper presents a concept of a rainbow of followers' attributes, or personal attributes of followers. A rainbow is comprised of a certain unity of colors, and so is the rainbow of followers' attributes - should one color or attribute fall out of place, the rainbow is not complete. Determining the most effective personal attributes of followers facilitates an understanding of behaviors of both - leaders and followers. Current paper attempts to comprehensively display the functionality and importance of proposed follower attributes and their application in the work place. 


\section{PROPOSED RAINBOW OF FOLLOWERS' ATTRIBUTES}

An attempt to derive a synopsis of the most effective attributes resulted in a list extensively supported by the literature. Current paper introduces a new perspective on personal attributes of followers, based on the list of attributes proposed by Antelo, Prilipko, and Sheridan-Pereira (2010) and Henderson (2008) . "Attribute," by definition, is "something attributed as belonging to a person, thing, group, etc.; a quality, character, characteristic or property" (Attribute, 2010). The notion of an attribute can be enhanced by the concept of an attribution theory, developed by Kelley (1992). Attribution theory aims to explain the ways individuals judge others, based on the meaning they attribute to a specific behavior. Personal attributes of followers are examined below, being thoroughly supported by theories, examples, illustrative comparisons and practical strategies for self-improvement.

\section{Facility for Interpersonal Relations}

Although literature is replete with information covering some aspects of interpersonal relations, its focus is on such areas as communication, negotiation and motivation. On the other side, attention has been given to interpersonal skills and emotional intelligence. Clydesdale (2009) believes that there is very little information offered on interpersonal relationship management (p.179). The area of our research falls into the category of developing peer relations, or interpersonal relations with other followers. Considering that the development and advancement of interpersonal relationship skills is a life-time process, the question remains whether the subject can be taught. According to Clydesdale (2009), it can be "taught by drawing on a broader training approach with includes motivation, cognitive, emotional, behavior and personality" (pp.179-180).

Strategies for Improvement. To explain the formation of relationships, the concept of "mutually understood common ground" was introduced by Ricardi and Kurtz (1983). In accordance with this concept, "as individuals share time and experiences together and reveal their backgrounds, interests, and beliefs to each other through communication, they establish common ground that is needed in the development of trust and relationship" (Slater, 2008, p.62). "Knowing people means figuring people out - finding out what they hold true and dear and what their values are and their skills, weaknesses, and strengths" (Slater, 2008, p.62). Knowing one's colleagues well serves as means of building relationships that encourage effective followership.

The ultimate goal of effective followers is to strive towards cultivating a nurturing interpersonal work climate with other team members. Respectful, harmonious relationships with coworkers are a manifestation of a social commitment leading to one's feelings of acceptance in the work place, contention and self-efficacy. According to Slater (2008), "real listening builds trust, and trust is the foundation of successful relationships. Listening to find out the issue is a basic skill that is also used in conflict resolution, an essential strategy that is also important in maintaining relationships" (p.63).

\section{Facility for Group Relations and Functions}

"Great thinking neither begins nor ends with a single person. Together talented people can perform dramatically better than they ever could as individuals" (Menkes, 2005, p.70). The fundamental principle of social relationships is believed to be the "reciprocity principle," or the tendency to treat others as they have treated us. In China Confucius claimed the reciprocity principle as "the rule of practice for all one's life" (Wong, 1939, p.413). Nevertheless, the reciprocity principle reveals that expectations can injure human relationships. Roman philosopher Seneca proposed a solution for that: He believed that individuals set their expectations too high when dealing with other people. His suggestion was to lower one's expectations and accept the fact that all people view things differently (Clydesdale, 2009, p.184).

Attribution theory mentioned previously also illustrates the role of expectations. The theory examines whether individuals attribute the cause of an action to a specific person or independent circumstances. When treating group relationships in the workplace, William Ury's presentation of attribution theory is illustrated as follows: "When we deal with someone we know and like we tend to attribute adverse events to extenuating circumstances, eg. 'I guess she didn't show up to the meeting because she was ill.' But when we deal with someone we don't like we tend to attribute the same events to the person's basic nature" (Ury, 1991, p.49). The author 
suggests that "The best time to lay the foundations for a good relationship is before a problem arrives" (Ury, 1991, pp.49-50). His bottom line advice is to purposefully build relationship capital.

Adam's Equity Theory was initially developed to address fairness in employee-employer relationships (Adams, 1965). Hatfield, Utne, and Traupmann (1979) applied the theory to intimate relationships, stating that individuals tend to make conclusions about the fairness of their contributions to relationships by comparing each party's ratio of input to outcomes and comparing their contributions to others in similar relationships. Should individuals conclude that they find themselves in an inequitable relationship, they can follow these avenues in order to restore equity: Change their own contributions to the relationship; convince the other party to change their contributions; persuade themselves that inequity never took place; or, as the most dramatic scenario, end the relationship (Hatfield et al., 1979).

Strategies for Improvement. According to Slater (2008), "Knowing people is crucial in developing the trust and respect that characterize collaborative relationships." The author explains: "Collaborative activities in which individuals lead, learn and influence others by building on their personal strengths and passions may satisfy higherlevel needs and tap higher levels of personal motivation and capacity. The most effective team efforts at any level in the organization demonstrate ability for any and all members to lead the group at different times" (pp.58-60).

Pursuant to the concept of Psychological Contracts by Robinson and Morrison (2000), an individual has certain beliefs about what he thinks is expected of another in a relationship. The concept suggests that when individuals are involved in a relationship, they have certain expectations about what the given relationship is going to bring. These expectations become so strongly established in people that they expect others to act according to those expectations as if they were legally confirmed in a document. As a result, should those expectations happen not to be met, individuals feel as if trust was brutally shattered. Argyle and Henderson (1985) have identified major categories of conflict with co-workers as interpersonal conflicts or work-matter conflicts. In order to maintain healthy work relationships, they suggest following 'Rules for co-workers,' which include such rules as "Accept one's fair share of work load," and "don't criticize the co-worker publicly."

\section{Tolerance}

"Tolerance is the ability to accept something while disapproving of it" (Tolerance, 2010). Followers are expected to exhibit a reasonable amount of tolerance when working individually or as a team. "In practice, tolerance indicates followers' support of practices, actions or decisions carried out by management and coworkers in spite of their intrinsic disagreement with such actions" (Antelo, Prilipko, \& Sheridan-Pereira, 2010). Power seems to be linked to elements of intensity of tolerance. In a study about the use of power in the supervisory relationship from supervisees' perspectives it was suggested that "supervisors' power practices included discussions of power, empowering supervisees, promoting an atmosphere of safety, collaboration with supervisees, imposition of style/orientation, and misuses of power, such as violation of confidentiality." The practices used by the supervisees included, supervisee-peer power, supervisees as consumers, and withholding information (Murphy and Wright, 2005).

Strategies for Improvement. In many workplace settings individuals find themselves dealing with people who are hard to develop relationships with, or, the so-called 'difficult people.' Duff and Hollingshead (1968) assert that certain individuals are often labeled as 'difficult' or 'bad' because they tend to create difficulties in other people's work. Finlay (2005) concludes that "'difficulty' is a subjective term and emerges within particular relationships set in particular contexts. It is associated with how work is made more difficult by a particular person and at times this may actually relate not to individuals, but to the processes involved." Thus, another sub-category of tolerance is identified among followers - tolerance towards co-workers; co-workers who appear to betray confidence, break the rules, "pass the buck," have uncommon morals and personal agendas. In her book "Fierce Conversations: Achieving Success at Work and in Life, One Conversation at a Time," Scott (2002) claims powerful conversations to be a step-by-step tool that will enhance one's tolerance towards 'impossible' colleagues, build breakthrough relationships with them, teach one the ways to expand, enrich and enjoy the territory that one is faced to explore with colleagues, increase clarity in work relationships and improve overall understanding in the workplace. 


\section{Conceptual Understanding}

Zaccaro (2000) introduces the empirical evidence for the proposed bond between high-level conceptual skills and performance. He states that "these skills include the ability to abstract a meaningful pattern, through processes of differentiation and integration, from a complex array of information. They also include the ability to develop novel and innovative solutions to complex organizational problems" (p.94). These skills are referred to as "conceptual capacity" (Jacobs and Jaques, 1987). These cognitive capacities, including creative and divergent thinking skills are considered to be distinct from the concept of mental ability or intelligence, which, in turn, are reviewed as follows. Nevertheless, the correlation between the two is found to be noteworthy.

It is believed that the best way to fully understand a subject, is to teach it to others. Menkes (2005) assumes that this is because "effective teaching requires an ability to clearly communicate issues as well as the capacity to identify and correct misunderstandings. ...Each is forced to actively struggle with the limitations in his or her own thinking and the challenges or identifying the weaknesses in the thinking of others" (p.272). Another simple but gripping assumption introduced by Menkes (2005) is that "the way our minds process information leads us to draw unwarranted conclusions and take immediate action without thinking first. This comes as the result of the way our brains have evolved over millions of years" (p.133). For the followers it is a common hindrance in their everyday work environment - to leap into an immediate conclusion ignoring the necessity of taking the time to carefully evaluate the situation at hand.

Strategies for Improvement. Being able to do a task well requires on the part of the followers, an understanding of the information related to the job. In this light, leaders as well as followers can use different strategies to acquire the required knowledge. "Empowerment seems to describe many of the dynamics inherent in the relationship that links effective, independent-thinking followers with effective leaders" (Lee,1991). The author states that effective followers are those individuals who are able to perform conceptual transfer to solve task-related problems. He suggests that effective followers are characterized as having: "Personal integrity that demands loyalty to the organization and willingness to act in their own beliefs; an understanding of the organization and their contributions to it; versatility, and responsibility" (Lee, 1991).

\section{Facility for Learning and Embracing Change}

Critical thinking is viewed as a pre-requisite for the processes of learning and embracing change. "Critical thinking is reasonable, reflective thinking that is focused on what to think or do. It requires an ability to recognize problems, gather pertinent information, interpret data, appraise evidence, and to evaluate lines of thinking, points of view, and personal insights that might contribute to the framing of logical, effective, reality-based action" (Pierce, 1990). Jenkins (1999) suggests that learning may occur through one of two processes. The first is the so-called 'ahha' experience. That is when an individual finally "grasps a new concept and the light bulb comes on..." The second process is the BFO, or blinding flash of the obvious" (p.19). Let us gradually flow to present the BFO concept by bringing in the chair example below.

Who has never sat in an uncomfortable chair? Does one truly need to continue utilizing that chair if it does not adhere to his comfort standards and causes misery day after day? There are two ways out of this situation. First, one can Learn to adjust the chair by applying auxiliary means (eg.cushions, etc.) to bring it to the desired level of comfort. Second, one can proceed to more drastic measures and Change the chair entirely to another one. This analogy is presented in order to portray the functionality of two fundamental approaches in the workplace, Learning and embracing Change, as a suggested attribute of an effective follower.

Change is a constant flow that is witnessed in human bodies, work relationships, energy level, emotions, career, etc. "Our days are a kaleidoscope. Every instant a change takes place. ... New harmonies, new contrasts, new combinations of every sort. ... The most familiar people stand each moment in some new relation to each other, to their work, to surrounding objects" (Beecher, 2010). In a physical universe change is constant. In Feng Shui, change is accepted as a gift; change is embraced and invited to make lives better. When one changes, there comes time to realize that the surrounding reality needs to change as well in order to accurately support the person as what he has become. 
Strategies for Improvement. Feng Shui suggests that when one feels the need to change something in the environment - be it one's office, work relationships, way of connecting with clients or other - it is imperative to follow through as quickly as possible. By doing so, one embraces new ways of thinking, feeling, acting, and moving forward with one's life. Those who follow through and make updates to their environments are following their true instincts and are tuning their surroundings in harmony with their growth and development (Collins, 2000, p.15). What happens if one feels the need for change, but leaves things the way they are? Work, relationships and lives then become anemic and spiritless. People's motivation and vigor is nurtured by change. If one's instincts to change are ignored, then vitality evaporates like the magic scent of an apple pie when it gets cold.

Workplace and workplace relationships may be pictured as common everyday things that exist because they are supposed to be there, simply because someone placed them there one day, like a decoration artwork on the wall. Artwork happens to collect dust too, and gets hackneyed over time. When an office, work relationships or other work-related circumstances start "yelling" at one that it is high time for a change, it is helpful to keep in mind that changing things provide support and comfort, adjusting to the new "you," and, on the other hand, change does not need to last forever. Cangemi and Miller (2007) refer to leadership's expectations of employees as written in a psychological contract of one of the US organizations in 2001: "Be willing to accept change: Change is inevitable. Those of us who adapt to change the quickest will be the most successful" (p.408).

\section{Facility for Effective Communication}

Ability to deliver both positive and negative news in the most appropriate way requires experiences, courage, and skills. Followers' challenge is to be able to communicate new perspectives with respect regardless of whether their ideas are accepted or not (Antelo, Prilipko, \& Sheridan-Pereira, 2010). Verbal communication implies the words and their meaning along with the content of actual interaction. Dimensions of verbal communication include "articulation, wording, and an approach to communication based on context" (Slater, 2008, p.64). Wording is presented as the ability to carefully choose words. Context is a frame of the situation being discussed or information presented. The content of the followers' verbal behavior is crucial in nurturing relationships with management, fellow colleagues and clients.

Strategies for Improvement. The importance of non-verbal communication is seldom acknowledged as opposed to verbal. "Recognition of the important role non-verbal communication plays in interpersonal interaction is a fairly recent development in communication research. Approximately $70 \%$ of our communication is non-verbal. Moreover, non-verbal communication is instrumental in conveying attitudes and emotional meaning. As such, nonverbal behavior is effective in reducing conflict and promoting positive relationships" (Slater, 2008, p.64-65).

Lambert (1988) presents the following elements of communication, which he also regards as strategies: Inquiry, reflection, skillful dialogue, and problem solving. He identifies the following key communication skills: Listening, verbal and non-verbal behavior, openness, empathy, and other competencies related to emotional intelligence. Hudson and Glomb (1997) propose the following communication strategies: Problem solving, planning cooperatively, negotiating, and conflict resolution. They assert that verbal and non-verbal skills are the basic communication skills and are the most essential. Welch (1998) lists several prerequisites of effective communication skills: Decision-making, consensus, and the resolution of conflict.

\section{Reliability as a Group Member}

Reliability as a group member is a cornerstone of one's reputation in the workplace. Good followers "trust and work effectively with others, embrace change, perform their job competently, identify with the leader, and share the leader's vision" (Latour and Rast, 2004). Follower reliability as a group member is dependent upon professional collaboration, trust, respect for the expertise of fellow group members and mutual interdependence for success. Effective followers recognize and nurture followership capacity in their colleagues by providing them with the opportunity to learn from each other and develop followership skills in supportive and collaborative atmosphere.

Strategies for Improvement . One intriguing approach to handle group situations is embedded in the ways that individuals view circumstances that they find themselves in: They may view situations as either threats or 
opportunities. Naidoo (2005) asserts that "labeling situations as threats may elicit a more cautious, avoidance orientation, whereas labeling them as opportunities may foster a more creative, approach orientation." Thus, a follower's responsibility is to be able to discern the emotional state of his group when facing a challenge at work and be able to create a positive atmosphere leading them to view the situation as an opportunity to grow and learn, fostering the group's understanding of each other's support and cohesiveness along with a sense of reliability.

Other strategies suggested to increase one's reliability as a group member include the following: Supporting team members by sharing their view and sharing thoughts with them; providing them with accurate information without withholding facts; performing at the same pace and being patient and respectful towards their chosen pace; being patient with their new ideas and giving them time to develop those ideas. Additional strategies suggested to enhance one's reliability within a group are to facilitate the group's distribution of the work load by balancing it optimally across the team, and be prepared to sacrifice.

\section{Facility for Contribution to the Group}

Followers carry a responsibility for creating a culture that would unleash the creativity and inner talents of its members; a culture that would support the followers' natural desire to contribute to a group. The key objective is to "unlock those beliefs and desires and enable everyone to become the leader who lies within" (Barth, 2003, p.62). Cangemi \& Miller (2007) provide a definition of teamwork implemented by one of the US organizations in 2001: "...a team is not a team until each member of the group is aware of how his or her behavior affects the entire team" (p.404).

Strategies for Improvement. Positive psychological states of followers stem from relational connections with their fellow workers. According to Reis and Gable (2003) and Dutton and Heaphy (2003), interactions with others are crucial for energizing people at work. Miller and Stiver (1997) (as cited in Spreitzer et al., 2005) suggest that "vitality - what they term zest - comes from relational connections with others" (p.539). Quinn (2007) contends that "the higher quality of the connection between two people, ..the more energy those people will feel" (p.74). Therefore, experiencing positive interactions with colleagues is a key to one's willingness to contribute to the group's work. When experiencing continual, ongoing interactions with the group members, individuals' positive spirit and energy naturally result in a process of contributing to the group.

\section{Emotional Intelligence}

According to Robbins and Judge (2009), emotional intelligence is one's ability to be "self-aware..., detect emotions in others, and manage emotional cues and information" (p.264). Mayer and Salovey (1997) present emotional intelligence as "the ability to perceive emotions, to access and generate emotions so as to assist thought, to understand emotions and emotional knowledge, and to reflectively regulate emotions so as to promote emotional and intellectual growth." In addition to emotional intelligence, the notion of political skill ought to be mentioned as well. It has been defined as "the ability to effectively understand others at work, and to use such knowledge to influence others to act in ways that enhance one's personal and/or organizational objectives" (Ferris et al., 2005, p.127). "As such, politically skilled individuals combine social astuteness with the capacity to adjust their behavior to different and changing situational demands in a manner that appears sincere, inspires support and trust, and effectively influences and controls the responses of others" (Liu et al., 2007, p.147).

Strategies for Improvement . Emotional intelligence contributes to effective followership as followers must be able to anticipate how their colleagues, clientele and management will react to various circumstances and manage these reactions in the most effective way. The most beneficial self-improvement areas for followers are suggested as follows: Emotional self-awareness, managing emotions, harnessing emotions productively, empathy and handling relationships. Followers with a high level of emotional intelligence are expected to possess control over their own behavior as well as express themselves in a graceful and appropriate manner. Moreover, emotionally intelligent followers are known to more consistently exhibit charismatic behaviors. 


\section{Facility for Supporting Others}

Facility for supporting others does not only imply the ability to provide support of emotional needs, but also the capacity to support the innovative ideas and creativity of other coworkers. This attribute is also associated with the ability of the follower to overcome problematic situations. The ability to listen to and understand others is a prerequisite to the ability of providing support to them. Covey (1989) calls it "listening empathetically" and defines it as the fifth habit of highly effective individuals, which is "Seek to understand, then to be understood." According to Goleman (1995), "the key to intuiting another's feelings is in the ability to read non-verbal channels: tone of voice, gesture, facial expression, and the like" (p.96).

Strategies for Improvement . "Approachibility conveys an attitude that invites communication" (Slater, 2008, p.65). One way to be identified as easily approachable, is to be in the 'center,' to be amongst others, as opposed to being at the 'top,' or on the 'side,' selfishly focusing on individual agenda. In addition to approachability, the other quality such as openness plays a dominant role as a facility for supporting others. To be able to provide support to others, individuals are to be open and trustworthy. "Openness is related to the honest sharing and disclosure of information, both personal and professional. To become fully trusted we must be open" (Kouzes and Posner, 1999).

One of the five domains of emotional intelligence described by Goleman (1995), empathy, "involves identifying the emotions of another person and being able to see the situation from that other person's perspective." He suggests implementing the concept of 'mirroring,' whereby one repeats the words of one's 'fellow combatant' in order to capture that individual's thoughts and feelings (Goleman, 1995). An "Invisible Man" approach suggested by Prilipko (2010), - "the ability to dissolve in the person that one is working with in order to better understand and feel the state that person is currently in" is provided here as a fundamental principle of knowing one in order to provide an individual with support needed.

"Having the ability to place oneself in another person's mood and state of being allows one to find the most optimal approach to that particular individual. By 'invisibly dissolving' in a person and finding out the other person's level of fatigue, level of thirst or hunger, frustration, fear, anger or other emotions, one becomes capable of comprehending the moral state the other person is in, and, therefore, capable of finding a better, individual approach based on a thorough emotionally intelligent foundation" (Prilipko, 2010).

\section{Flexibility}

According to Kolb's (1984) theory of integrative development, "the ability to respond flexibly to change has a strong influence on a person's adaptation and growth over the life span. This trait is called "adaptive flexibility." People with high degrees of adaptive flexibility are readily able to adapt their style of learning to the demands of the learning situation." Good followers are capable of developing cognitive flexibility, which allows them to effortlessly shift from one task to another, multitask, manage assignments well, and prioritize accordingly. When exhibiting emotional flexibility, followers are able to express their full range of emotions appropriate to the situation at hand (Antelo, Prilipko, \& Sheridan-Pereira, 2010).

As individuals enter this world and begin their development, they are taught the traditional ways of doing things - working, speaking, performing, establishing relationships, etc. - or, in other words, "thinking-inside-thebox" type of actions. Cangemi and Miller (2007) find that "we are shaped into accepting grass as green and cows as brown. At home, the parents' work is inviolate; in school, we learn that the teacher's approach to solving a problem is the only acceptable approach; and, as we enter the workforce, that the boss is "always right" (p.401).

Strategies for Improvement . In accordance with Shutz (1996), "positive self-esteem is a feeling about oneself, a feeling that helps one feel alive, significant, competent, self-aware, self-empowered, smart, encouraged and free to think. In other words, one feels comfortable to think "outside-of-the-box." When followers clearly display positive self-esteem feelings, work atmosphere is characterized by: "Openness, appreciation, self-determination, freedom, recognition, participation, experimentation, freedom from fear, and self-confidence." Fostering an atmosphere that encourages freedom, creativity, and a "breaking-out-of-the-box" attitude is possible if psychological needs of the followers are revealed. 
It is the followers' responsibility to acknowledge the fact that workforce is not made of wooden \#2 pencils who line up to be a number of identical performers. On the opposite, creative and flexible workforce is rather a zigzag line of multicolored crayons, each possessing a unique array of skills, talents and mindsets. What happens when an army of \#2 pencils and a party of crayons start a project at the same time as two teams? Pencils end up with a boring, predictable sketch of straight black lines, with the same drawing, all facing the same direction. Now, what does the joyful versicolor crayons' final project look like? A hurricane party-like burst of creativity, filled with unpredictable design and craziness of limits-free imagination, reflecting one feature in common: An intentional diversity of personality, skills and viewpoints. On one hand, followers feel comfortable expressing themselves free of conventional organizational suggestions; on the other hand, the company is in possession of extraordinaire unconventional solution, which paves the way to further creativity and more advanced flexible achievements.

\section{Motivation for Goal Accomplishment}

Leaders appreciate self-motivation in followers as opposed to artificial motivation guided by financial rewards, perks, or other quasi-stimulators as driving sources. Followers are courageous and honest individuals who "formulate their own meaning of life rather than pursue societal goals such as money, status, and fame. They do not compete for leadership or power. Instead, they cooperate to accomplish goals" (Kelley, 1992).

Strategies for Improvement. Imagine two teams consisting of 10 members competing in a cooking contest. Both teams are motivated to win and motivation of each single contestant within one group is expected to be on a similar level since all 10 members are united by a common goal - to outperform the competitor. However, motivation is not enough. The secret ingredient in this cooking scenario is creativity. According to Stoll (2008), "creativity is more likely to be enhanced, developed and supported through collective rather than individual endeavor, in organizations that develop strong communities of practice" (as cited in Harris, 2009, p.10). Creative followers are in charge of setting the right atmosphere, in which friendliness and creativity will flourish. By doing so, they virtually remove obstacles that prevent people from working together. In such environment individuals are prone to actively communicate with one another, learn from each other and support each other through pleasant interaction, collaboration, dialogue and even disagreement.

\section{RESEARCH DESIGN AND SETTING}

The current study is a component of an ongoing research on the process of leadership and followership and was conducted in natural organizational settings where leaders and followers were involved in real work situations. Although the final goal is to analyze and compare the data collected in Russia, Belarus, the United States, Bolivia, Mexico, and Italy, this paper presents some of the results of the first two countries selected - Russia and Belarus.

The basic quantitative inquiry system for this study is the Statistical Survey Design. In addition, correlation procedures are applied to assess selected variables and their relationships. Some demographic data such as gender, age, education, and experience were collected. The survey instruments include questions related to personal attributes. Descriptive and inferential statistics are used for the data analysis in an attempt to provide answers to the research problem.

\section{SAMPLE AND DATA COLLECTION}

The total sample with representatives of six countries mentioned amounts to 400 members. The specific sample being reviewed in this paper illustrates the results of 106 participants from Russia and Belarus. This subgroup is composed of leaders and followers who are currently working as managers, supervisors and subordinates. These individuals belong to business, educational, health care organizations, and other service institutions.

Data were collected online through surveymonkey.com during 2009 and the spring 2010. A survey instrumentation composed of three sections was used for data collection. The FSAI-1, Follower Self Assessment Inventory - short form, the LFAI, Leader Follower Assessment Inventory, and the FSAI-2 Follower Self Assessment Inventory. These questionnaires are reliable in accordance with Crombach's Alpha measurement of .85 (Henderson and Antelo, 2007). 


\section{PRELIMINARY FINDINGS}

According to the initial data analysis, participants included $26.88 \%$ males and $73.12 \%$ females. The majority of the members of the sample are from Russia (62.26\%), Belarus (30.19\%) and other countries (7.55\%).

Based on the results shown in Table 1, the top three characteristics with the highest mean values are reliability as a group member, facility for supporting others and facility for contribution to the group. Indeed, these attributes are coherently related to one another, representing the overall group-work culture. An intriguing finding is that the mean of facility for interpersonal relations (3.06) is considerably lower than the mean of reliability as a group member (3.74). Since $75.23 \%$ of the respondents are over the age of 30 (the average age of the respondents of the given countries is equal to 34 years of age), that leads us to conclude that having their roots in the USSR era, which is characterized by highly collectivistic period of time, the respondents involuntarily have an inclination towards the group work and camaraderie, and are comfortable in the atmosphere of togetherness, including respondents in their early thirties. "Collectivism emphasizes a tight social framework in which people expect others in groups of which they are a part to look after them and protect them" (Robbins \& Judge, 2009, p.124).

Furthermore, the concept of emotional intelligence is not well known in the sample countries. Therefore, the respondents in Russia and Belarus had a different understanding of its meaning as opposed to interviewees in the U.S.A. and other countries. The results of such attributes as tolerance and learning and embracing change are also predictably low due to cultural uniqueness. In other words, tolerance among followers in the countries of sample is viewed as tolerance towards such predictable but uncontrollable events as weeks of salary postponing, having to work in no-air-conditioner facilities, or having hot and cold water shut off, whereas in the U.S.A. tolerance is viewed as tolerance to not so severe circumstances. Current understanding of tolerance among respondents of the sample population may also be compared to Robbins and Judge's (2009) notion of "uncertainty avoidance," which is "a national culture attribute that describes the extent to which a society feels threatened by uncertain and ambiguous situations and tried to avoid them. In cultures that score high on uncertainty avoidance, people have an increased level of anxiety about uncertainty and ambiguity and use laws and controls to reduce uncertainty" (pp.124-125). Gannon and Pillai (2010) view uncertainty avoidance or "(acceptance of risk" or the degree to which members of a given society deal with the uncertainty and risk of everyday life and prefer to work with long-term acquaintances and friends rather than with strangers" (p.11).

Table 1. Mean values of the followers' attributes

\begin{tabular}{|l|c|c|c|}
\hline \multicolumn{1}{|c|}{ Attribute } & Mean & Std. Error & Std. Deviation \\
\hline Reliability as a group member & 3.74 & .089 & .919 \\
Supporting others & 3.47 & .093 & .958 \\
Contribution to the group & 3.39 & .079 & .811 \\
Conceptual understanding & 3.32 & .087 & .900 \\
Emotional intelligence & 3.20 & .095 & .980 \\
Group relations & 3.20 & .081 & .833 \\
Effective communication & 3.16 & .086 & .885 \\
Flexibility & 3.14 & .099 & 1.018 \\
Motivation for goal accomplishment & 3.13 & .089 & .916 \\
Interpersonal relations & 3.06 & .079 & .815 \\
Tolerance & 3.02 & .107 & .093 \\
Learning and embracing change & 2.90 & & .955 \\
\hline
\end{tabular}

Note: $\mathrm{N}=106$ research participants.

According to Yukl (2002), "The 'feminine advantage' perspective contends that women are more skilled at inclusiveness, interpersonal relations, power sharing, and the nurturing of followers" (p.412), and as a consequence, women should be superior leaders (Carr-Rufino, 1993; Grant, 1988; Helgeson, 1990; Loden, 1985; Rosener, 1990, 1995). However, the results of the study presented in Table 2 indicate that there is no significant difference between female and male ratings of all attributes. Females rated their facility for learning and embracing change on the lowest level possible, and males indicated their facility for interpersonal relations, and facility for learning and embracing change as their lowest-rated attributes. Additionally, a Pearson Moment Correlation procedures were 
performed to these subgroups and results indicated that females' and males' ratings are correlated ( $\mathrm{r}=77)$. Finally, statistical procedures were performed to determine the reliability of the instruments used. Results proved the instruments to be highly reliable having a Cronbach's Alpha coefficient of .990.

Table 2. Mean values by gender

\begin{tabular}{|l|cc|cc|}
\hline \multicolumn{1}{|c|}{ Followers' Attributes } & \multicolumn{2}{|c|}{ Female } & \multicolumn{2}{c|}{ Male } \\
Mean & Std. Dev. \\
\hline Interpersonal relations & Mean & Std. Dev. & 3 & $(0.89)$ \\
Group relations & 3.08 & $(0.77)$ & 3.13 & $(0.88)$ \\
Tolerance & 3.22 & $(0.80)$ & 3.07 & $(1.00)$ \\
Conceptual understanding & 3 & $(1.14)$ & 3.47 & $(0.96)$ \\
Learning and embracing change & 3.26 & $(0.86)$ & 3 & $(0.86)$ \\
Effective communication & 2.86 & $(0.98)$ & 3.17 & $(0.82)$ \\
Reliability as a group member. & 3.16 & $(0.90)$ & 3.57 & $(0.96)$ \\
Contribution to the group & 3.80 & $(0.90)$ & 3.40 & $(0.88)$ \\
Emotional intelligence & 3.43 & $(0.75)$ & 3.30 & $(0.86)$ \\
Supporting others & 3.16 & $(1.01)$ & 3.23 & $(0.88)$ \\
Flexibility & 3.57 & $(0.96)$ & 3.23 & $(0.92)$ \\
Motivation for goal accomplishment & 3.11 & $(1.05)$ & 3.20 & $(0.91)$ \\
\hline
\end{tabular}

\section{CONCLUSIONS}

Similar to a yin-yang unity, effective leadership is inconceivable without effective followership. The ancient Chinese yin and yang are inseparable and present an endless unity: These two forces do not have a point of termination; they gradually flow to complete one another. Based on this comparison and the fact that leadership has received an exuberant amount of attention, we focus on followership as an attempt to fill the second scale pan. Although one cannot deny gradual progress in the overall understanding of followership, a number of questions remain unanswered. It is not known why individuals voluntarily submit to become followers (Van Vugt, 2006). Furthermore, it is not fully understood how follower attributes develop and advance over time; the follower behavior effectiveness is still in the shade; and, most certainly, it is not determined how followers think or understand followership situations they are in. On one hand, the process of the followers' attributes formation and development may be viewed from the perspective of a natural process of learning and gaining experience which occurs with time. On the other hand, there is no empirical research or evidence proving that followership qualities undergo a slow and painstaking development processes involving months or years, and there is no sufficient research referring to whether followers' attributes can be altered. In spite of that, we posit that the process of followers' attributes development can be portrayed as a staircase: A gradual progression from novice to intermediate to expert skill levels. However, it is critical to keep in mind that the process of follower attributes development is a unique process, which has its own route for each individual; there is no known general model for the development of followership skills.

In order to comprehensively portray the criticality of the attributes rainbow as a single unity we refer to the following comparison: An iron-man triathlon starts with a swim, continues with a race and finishes with a run. No matter how good one is at swimming, he will lose the race if his cycling or running skills are not at the same powerful level. It makes little sense to improve one's swim by a small increment when the other two skills are still too below to be compared. Similarly, one cannot be an expert at effective communication and neglect the ability of contribution to the group. All the follower attributes proposed can be visualized as a bag of tangerines. Should one fall out of the bag, the others will follow. In other words, the conclusion is straight-forward: No iron-man victory is possible if one skill is missing; no bag is complete if one fruit has fallen out; and rainbow is not a rainbow if one color is not in place. Effectively leveraging the 'follower capital' is a key success factor for virtually all organizations. Followers are challenged with the task of maximizing their knowledge and skills, ultimately resulting in innovation and increased organizational performance.

As it was mentioned earlier, participants have identified effective personal attributes considered critical for the leadership and followership processes. These attributes include reliability as a group member, supporting others, 
contribution to the group, and conceptual understanding. It was also revealed that the capability to learn and embrace change obtained the lowest rating. This may be an indicator of the complexity of the process for implementing change. In addition, reliability as a group member was the highest rated attribute. Overall findings suggest that personal characteristics are regarded to be essential in the followership process.

The results of the study reveal no significant difference between female and male ratings of all attributes. Also, it must be recognized that both females and males rated their reliability as a group member as the highest attribute. Learning and embracing change turned out to be the lowest-rated attribute among females. As for males, interpersonal relations, and learning and embracing change were among the lowest-rated attributes. It is possible for the followers to encounter great difficulty in modifying or changing critical attributes. Clearly, there is a need to analyze how these attributes can be changed and this is another route for future investigation.

To conclude, this article explored the implications of follower attributes proposed along with strategies directed towards further advancement of those follower capacities. Some of those strategies discussed included enhancing such communication skills as listening, the significance of verbal and non-verbal behaviors, openness, supporting others, member participation and engagement, creating atmosphere of viewing challenges as opportunities, empathy and courage to sharpen followership facilities that would benefit not just the followers themselves, but overall organizational mechanisms. Drawing on the facilities, skills, and resources of followers is fundamental in organizational structures. Nurturing followership capacity and inspiring others for personal development breakthroughs requires effort, unique insight and explicit skills on the part of the followers. Current investigation may serve as a vehicle for building followership understanding and as a guide to self-improvement. The followers' success in the long run will be measured by the organizational atmosphere they create, the emotional bond they have developed with management, coworkers and clientele, and, most centrally, by the number of other followers who they have inspired to become leaders within being followers.

\section{AUTHOR INFORMATION}

Evgenia Prilipko is a Ph.D. student with the concentration in Organizational Leadership at the University of the Incarnate Word, San Antonio, Texas. Her three Master's degrees are in the following areas: Teaching English and French, Global Economy and International Relations, and Organizational Communication and Development. Her research interests include leadership, assessment and development of leader attributes as well as followership, assessment and development of follower attributes.

Absael Antelo is an Associate Professor of the University of the Incarnate Word. Dr. Antelo has worked as President of the Bolivian Private University and of the Franz Tamayo University. He also served as a School Superintendent for the Educational Corporation Eagles' School. Dr. Antelo worked as a Vice President for Academic Affairs and Director of Graduate Studies at North Eastern University. His research is focused on leadership, intercultural learning, followership, and school administration.

Richard Henderson is a Professor of Education and the Coordinator for the Organizational Leadership Concentration of the Ph.D. Program at the University of the Incarnate Word, in San Antonio, Texas. He has been retained as a consultant by research and educational organizations. He is credited with the formulation and implementation of one of the Nation's first "performance pay" systems in education and he has designed management structures for institutions in the United States, Central, and South America. Dr. Henderson's current research projects include educational equity, educational law, and leadership development. His research is published in international, national and regional journals.

\section{REFERENCES}

1. $\quad$ Adams, J.S. (1965). "Inequity in social exchange" in Berkowitz, L. (Ed). Advances in Experimental Psychology, 2, 267-299. New York, NY: Academic Press.

2. Antelo, A. (2010). Lecture on "Assessing effective attributes of followers in a leadership process." Concepts of Leadership, University of the Incarnate Word, San Antonio, TX. 
3. Antelo, A., Prilipko, E.V., Sheridan-Pereira, M. (2010). Assessing effective attributes of followers in a leadership process. Paper presented at the 2010 European College Teaching and Learning Conference. Dublin, Ireland.

4. Argyle, M. \& Henderson, M. (1985). The anatomy of relationships. London: Heinemann.

5. Atchison, T. (2003). Followership: A practical guide to aligning leaders and followers. New York, NY: Health Administration Press.

6. Atkinson, S. (2004). Senior management relationships and trust: An exploratory study. Journal of Management Psychology, 19(6), 571-587.

7. Atkinson, S., \& Butcher, D. (2003). Trust in the context of management relationships: An empirical study. SAM Advanced Management Journal, Autumn, 24-35.

8. Attribute,(2010). Retrieved from www.dictionary.reference.com/browse/attribute

9. Avolio, B.J. (2007). Promoting more integrative strategies for leadership theory building. American Psychologist, 62, 25-33.

10. Baltes, M.M. \& Carstensen, L.L. (1991). Possible selves and their fertility in the process of successful aging: A commentary on Cross and Markus. Human Development, 34, 256-260.

11. Barth, R. (2003). Lessons learned: Shaping relationships and the culture of the workplace. Thousand Oaks, CA: Corwin Press.

12. Beecher, H.W. (2010). Famous quotes and authors. Retrieved from http://www.famousquotesandauthors.com/topics/change_quotes.html

13. Boerner, S., E, \& Griesser, D. (2007). Follower behavior and organizational performance: The Impact of transformational leaders. Journal of Leadership \& Organizational Studies, 13(3), 15-26.

14. Cangemi, J. \& Miller, R. (2007). Breaking-out-of-the-box in organizations :Structuring a positive climate for the development of creativity in the workplace. The Journal of Management Development, 26(5), 401410 .

15. Carr-Rufino, N. (1993). The promotable woman: Advancing through leadership skills. Belmont, CA: Wadsworth.

16. Chi, M. T. H., Glaser, R. \& Farr, M.J. (1988). The nature of expertise. Hillsdale, NJ: Erlbaum.

17. Clydesdale, G. (2009). Management education's blind spot: Management of workplace relations. Journal of European Industrial Training, 33(2), 178-191.

18. Collins, T.K. (2000). The Western guide to Feng Shui: Room by room. Carlbad, CA: Hay House.

19. Cooper, J. \& Ng, K.M. (2009). Trait emotional intelligence and perceived supervisory working alliance of counseling trainees and their supervisors in agency settings. International Journal for the Advancement of Counselling, 31 (3), 145-157.

20. Covey, S.R. (1989). The seven habits of highly effective people. NY: Fireside.

21. Day, D.V., Harrison, M.M., \& Halpin, S.M. (2009). An integrative approach to leader development: Connecting adult development, identity, and expertise. New York, NY: Psychology Press.

22. de Jong, R.D. (2009). Review of the book "The art of followership: How great followers create great leaders and organizations" by Riggio, A.E., Chaleff, I., \& Lipman-Blumen, J. San-Francisco, CA: JosseyBass.

23. Duff, R. \& Hollingshead, A. (1968). Sickness and society. New York, NY: Harper \& Row.

24. Dutton, J.E., \& Heaphy, E.D. (2003). The power of high-quality connections at work. In K.S. Cameron, J.E., Dutton, \& R.E. Quinn (Eds.), Positive organizational scholarship (pp.263-278). San Francisco: Berrett-Koehler Publishers.

25. Emotional Intelligence, 2010. Retrieved from http://en.wikipedia.org/wiki/Emotional intelligence

26. Ericsson, K. A., (1996). The acquisition of expert performance: An introduction to some of the issues. In "The Road to Excellence: The Acquisition of Expert Performance in the Arts and Sciences, Sports, and Games”, Ericsson, K.A., ed. Mahwah, NJ: Erlbaum.

27. Ericsson, K. A., \& Lehmann, A.C. (1996). Expert and exceptional performance: Evidence on maximal adaptations on task constraints. Annual Review of Psychology, 47, 273-305.

28. Ferris, G.R., Perrewe, P.L., Anthony, W.P., \& Gilmore, D.C. (2000). Political skill at work. Organizational Dynamics, 28(4), 25-37.

29. Ferris, G.R., Treadway, D.C., Kolodinsky, R.W., Hochwarter, W.A., Kacmar, C.J., and Douglas, C., et al., (2005). Development and validation of the Political Skill Inventory. Journal of Management, 31, 126-152.

30. Finlay, L. (2005). Difficult encounters. Nursing Management, 12(1), 31-36. 
31. Gannon, M.J., Pillai, R. (2010). Understanding global cultures: Metaphorical journeys through 29 nations, clusters of nations, continents, and diversity. Thousand Oaks, CA: SAGE Publications, Inc.

32. George, J.M. (2000). Emotions and leadership: The role of emotional intelligence. Human Relations, 53, 1027-1055.

33. Giammattelo, M. \& Giammattelo, D. (1981). Forces on Leadership. Reston, VR: National Association of Secondary School Principals.

34. Goffee, R., \& Jones, G. (2006). The art of followership. European Business Forum, 25, 22-26.

35. Goleman, D. (1995). Emotional intelligence: Why it can matter more than IQ. New York: Bantam.

36. Gould, L.J., Stapley, L.F., \& Stein, M. (2004). Experiential learning in organizations: Applications of the Tavistock Group Relations Approach. London: H.Karnac Books Ltd.

37. Graen, G.B. (2009). Excellence in socio-technical teamwork requires both cognitive and emotional boding. American Psychologist, 64 (1), 52-53.

38. Grant, J. (1988). Women as managers: What they can offer to organizations. Organizational Dynamics, 56-63.

39. Grint, K. (2000). The arts of leadership. Oxford: Oxford University Press.

40. Hackman, J.R., \& Wageman, R. (2007). Asking the right questions about leadership. American Psychologist, 62(1), 43-47.

41. Hatfield, E., Utne, M.K., \& Traupmann, K. (1979). "Equity theory and intimate relationships" in Burgess, R.L., \& Huston, T.L. (Eds). Social Exchange in Developing Relationships. New York, NY: Academic Press.

42. Harris, A. (2009). Creative leadership: Developing future leaders. British Educational Leadership, Management \& Administration Society (BELMAS), 23(1), 9-11.

43. Heider, F. (1958). The psychology of interpersonal relations. New York: Wiley.

44. Helgeson, S. (1990). The female advantage: Women's ways of leadership. New York: Doubleday/Currency.

45. Henderson, R.L. (2008). "Back to the Basics of Leadership: Understanding Leadership Attribute Assessment and Development." Conference Proceedings of the International Conference on College Teaching. (\#240T). San Juan, Puerto Rico.

46. Henderson, R., \& Antelo, A. (2007). "The Scholar Practitioner: The View of Practicing Organizational Leaders." Conference Proceedings of the International Conference on College Teaching. (\#306T). Venice, Italy.

47. Hollander, E.P., \& Kelly, D.R. (1992). Appraising relational qualities of leadership and followership. International Journal of Psychology, 27, 289-290.

48. Hudson, P. \& Glomb, N. (1997). If it takes two to tango then why not teach both partners to dance? Collaboration instruction for all educators. Journal of Learning Disabilities, 30(4), 442-448.

49. Hur, M.H. (2008). Exploring differences in leadership styles: A study of manager tasks, follower characteristics, and task environments in Korean human service organizations. Social behavior and personality, 36(3), 359-372.

50. Jacobs, T.O., \& Jaques, E. (1987). Leadership in complex systems. In Zeidner, J. (Ed.), Human productivity enhancement. New York: Praeger.

51. Johnson, C. (1994). Empowering the organization through professional talk. Dubuque, LA: Kendall/Hunt.

52. Kellett, J.B., Humphrey, R.H., \& Sleeth, R.G. (2006). Empathy and the emergence of task and relations leaders. The Leadership Quarterly, 17, 146-162.

53. Kelley, R.E. (1988). In praise of followers. Harvard Business Review, 66, 142-148.

54. Kelley, R.E. (1992). The power of followership: How to create leaders people want to follow, and followers who lead themselves. New York: Doubleday.

55. Kolb, D.A. (1984). Experiential learning: Experience as the source of learning and development. Englewood Cliffs, NJ: Prentice-Hall.

56. Kouzes, J.M., \& Posner, B.Z. (1999). Encouraging the heart. San Francisco, CA: Jossey-Bass.

57. Lambert, L. (1998). Building leadership capacity in schools. Alexandria, VA: Association for Supervision and Curriculum Development.

58. Latour, S.M., \& Rast, V.J. (2004). Dynamic followership. Air \& Space Power Journal, 18(4), 1-7.

59. Lee, C. (1991). Followership: The Essence of Leadership. Training, $28(1), 27$. 
60. Lin, H.B. (2000). The art and science of Feng Shui: The ancient Chinese tradition of shaping fate. St. Paul, MN: Llewellyn Publications.

61. Liu, Y., Ferris, G.R., Xinko, R., Perrewe, P.L., Weitz, B., \& Xu, J. (2007). Dispositional antecedents and outcomes of political skill in organizations: A four-study investigation with convergence. Journal of Vocational Behavior, 71, 146-165.

62. Loden, M. (1985). Feminine leadership: or how to succeed in business without being one of the boys. New York, NY: Times Books.

63. Lundin, S.C., \& Lancaster, L.C. (1990). Beyond leadership: The importance of followership. Futurist, 24, $18-22$.

64. Major, D.A., Kozlowski, S.W., Chao, G.T., \& Gardner, P.D. (1995). A longitudinal investigation of newcomer expectations, early socialization outcomes, and the moderating effects of role development factors. Journal of Applied Psychology, 80, 418-431.

65. Mayer, J.D., \& Salovey, P. (1997). What is emotional intelligence? In P. Salovey \& D.J. Sluyter (Eds.), Emotional development and emotional intelligence: Educational implications (pp.3-34). New York: Basic Books.

66. Menkes, J. (2005). Executive intelligence: What all great leaders have. New York, NY: HarperCollins.

67. Miller, J.B., \& Stiver, I.P. (1997). The healing connection: How women form relationships in therapy and in life. Boston: Beacon Press.

68. Moss, S.. (2009). Cultivating the Regulatory Focus of Followers to Amplify Their Sensitivity to Transformational Leadership. Journal of Leadership \& Organizational Studies, 15(3), 241.

69. Murphy, M.J. \& Wright, D.W. (2005). Supervisees' perspectives of power use in supervision. Journal of Marital and Family Therapy, 31, (3), 283-295.

70. Naidoo, L.J. (2005). Leaders' effects on follower goal-striving processes. Working paper. University of Akron, Akron, $\mathrm{OH}$.

71. Nelson, B. (1996). Motivating today's employees. San Diego, CA: Nelson Motivation.

72. Nolan, J.S., \& Harty, H.F. (2001). Followership - leadership. Education, 104(3), 112-113.

73. Pierce, G. (1990, August). Critical thinking: The role of management education - developing managers to think critically. Paper presented at the Annual Conference on Critical Thinking and Education Reform. Rohne Park, CA.

74. Pleasure/Unpleasure principle, 2010. Retrieved from http://www.enotes.com/psychoanalysisencyclopedia/pleasure-unpleasure-principle

75. Prilipko, E.V. (2010). Presentation on Organizational Leadership Practicum, ORGL 8371, Practicum in Organizational Leadership, University of the Incarnate Word, San Antonio, TX.

76. Quinn, R.W. (2007). Energizing others in work connections. In Jane E. Dutton, \& Belle Rose Ragins (Eds.), Exploring positive relationships at work: Building a theoretical and research foundation (pp.7390). Mahwah, NJ: Lawrence Erlbaum Associates.

77. Raelin, J. (1997). A model of work-based learning. Organizational Science, 8, 563-578.

78. Reality principle, (2010). Retrieved from http://www.enotes.com/psychoanalysis-encyclopedia/realityprinciple

79. Reis, H.T., \& Gable, S.L. (2003). Toward a positive psychology of relationships. In C.L. Keyes, \& J. Haidt (Eds.), Flourishing: The positive person and the good life (pp.129-159). Washington, DC: American Psychological Association.

80. Riccardi, V.M., \& Kurtz, S.M. (1983). Communication and Counseling in Health Care. Springfield, IL: Charles C. Thomas.

81. Riggio, R.E., Chaleff, I., \& Lipman-Blumen, J. (2008). The art of followership: How great followers create great leaders and organizations. San Francisco, CA: Jossey-Bass.

82. Robbins, S.P., \& Judge, T.A. (2009). Organizational Behavior. Upper Saddle River, NJ: Prentice-Hall.

83. Rosener, J.B. (1990). Ways women lead. Harvard Business Review, 68(6), 119-125.

84. Rosener, J.B. (1995). America's competitive secret: Utilizing women as a management strategy. New York, NY: Oxford Univ. Press.

85. Schyns, B., \& Hansbrough, T. (2008). Why the brewery ran out of beer: The attribution of mistakes in a leadership context. Social Psychology, 39(3), 197-203.

86. Scott, S. (2002). Fierce conversations: Achieving success at work and in life, one conversation at a time. New York, NY: Viking Penguin. 
87. Shutz, W. (1996). Self-esteem: The key to productivity. Mill Valley, CA: Will Schutz Associates.

88. Slater, L. (2004). "Relationship-driven teaching cultivates collaboration and inclusion," Kappa Delta Pi Record 58-9.

89. Slater, L. (2008). Pathways to building leadership capacity. Educational Management Administration \& Leadership, 36(1), 55-69.

90. Sluss, D. M., Klimchak, M., \& Holmes, J.J. (2008). Perceived organizational support as a mediator between relational exchange and organizational identification, Journal of Vocational Behavior, 73 (3), $457-$ 464.

91. Smith, R. (1997). Defining leadership through followership. Annual Meeting of the National Communication Association. Chicago, IL.

92. Solovy, A. (2005). Followership. Hospitals and Health Networks. www.hhnmag.com

93. Spreitzer, G., Sutcliffe, K., Dutton, J., Sonenshein, S., \& Grant, A.M. (2005). A socially embedded model of thriving at work. Organization Science, 16(5), 537-549.

94. Stodgill, R., \& Coons, A.E. (1957). Leader behavior: Its description and measurement. Research Monograph, 88. Columbus, Ohio State University.

95. Stoll, L. (2008). Creative leadership: A challenge of our times. Paper presented at the American Educational Research Association, New York.

96. Tolerance,(2010). In Wikipedia The Free Encyclopedia. Retrieved from http://en.wikipedia.org/wiki/Toleration

97. Townsend, P.L., \& Gebhardt, J.E. (2003). The leadership-teamship-followership continuum. Leader to Leader, 29, 18-21.

98. Treadway, D.C., Hochwarter, W.A., Ferris, G.R., Kacmar, C.J., Douglas, C., Ammeter, A.P., et al. (2004). Leader political skill and employee reactions. The Leadership Quarterly, 15, 493-513.

99. Ury, W. (1991). Getting past no. New York, NY: Bantam Books.

100. Van Vugt, M. (2006). Evolutionary origins of leadership and followership. Personality and Social Psychology Review, 10(4), 354-371.

101. Van Vugt, M. (2009). Despotism, democracy, and the evolutionary dynamics of leadership and followership. American Psychologist, 54-56.

102. Vecchio, R.P. (1987). Effective followership: Leadership turned upside down. Journal of Business Strategies, 4, 39-47.

103. Vecchio, R.P. (2002). Leadership and gender advantage. The Leadership Quarterly, 13, 643-671.

104. Welch, M. (1998). Collaboration: Staying on the bandwagon. Journal of Teacher Education, 49(1), $26-37$.

105. Wiles, K. (1967). Supervision for better schools. Englewood Cliffs, NJ: Prentice-Hall.

106. Wong, C.A. (1939). The analects of Confucius, the great learning, the doctrine of the mean and the works of Mencius. New York, NY: Viking Press.

107. Yukl, G. (2002). Leadership in organizations. Upper Saddle River, NJ: Prentice-Hall.

108. Yukl, G. (2006). Leadership in organizations, $6^{\text {th }}$ ed. Upper Saddle Creek, NJ: Prentice-Hall.

109. Zaccaro, S.J. (2001). The nature of executive leadership: A conceptual and empirical analysis of success. Washington, DC: American Psychological Association.

110. Zaccaro, S. J., Mumford, M. D., Marks, M. A., Connelly, M. S., Threlfall, K. V., Gilbert, J., \& Fleishman, E. A. (1995). Cognitive and temperament determinants of Army leadership (Tech. Rep. for U.S. Army

Research Institute for the Behavioral and Social Sciences). Bethesda, MD: Management Research Institute. 